\title{
Pola Pemantapan Penataan Ruang Terbuka Hijau Untuk Kawasan Kota Berkembang Di Batu Sopang Kabupaten Paser
}

\author{
Strengthening Green Open Space Arrangement Pattern for Urban \\ Developing Areas in Batu Sopang, Paser Regency
}

\author{
Thomas Robert Hutauruk ${ }^{1, \mathrm{a})}$, Faizal Baharudin ${ }^{2, \mathrm{~b})}$, Afif Bizrie Mardhani ${ }^{3, \mathrm{c}} \boldsymbol{\&}$ \\ Mohammad Romadloni ${ }^{1)}$ \\ 1)Jurusan Manajemen, Sekolah Tinggi Ilmu Manajemen Indonesia, Samarinda. \\ 2) Jurusan Teknik Arsitektur, Fakultas Teknik, Universitas 17 Agustus 1945, Samarinda. \\ 3) Jurusan Teknik Sipil, Politeknik Negeri Samarinda, Samarinda.
}

Koresponden : ${ }^{a}$ thomas_huta@yahoo.com, ${ }^{b)}$ f4ical.fb@gmail.com \& ${ }^{c}$ fifa_yudhistira@gmail.com

\begin{abstract}
ABSTRAK
Tujuan penelitian ini adalah untuk memperolah gambaran lokasi yang cocok dan luas kawasan peruntukan Ruang Terbuka Hijau (RTH) yang memungkinkan ditempatkan di kawasan perkotaan Batu Sopang yang memiliki luas wilayah $\pm 1.614,5$ hektar dengan menerapkan konsep Green Spatial Planning (GSP). Metode yang digunakan adalah analisis spasial Peta Citra World View-3 - Bundle 8 Band - kategori Select Tasking/Fresh Archive < 90 Days skala $1: 5000$.

Hasil penelitian ini menunjukkan bahwa kondisi eksisting keberadaan RTH publik di Batu Sopang yang tersedia hanya mencapai $7,18 \%$ sehingga luas wilayah yang ada belum memenuhi standar kawasan perkotaan. Pada masa mendatang, perlu mempertahankan kondisi RTH yang ada, disamping juga diperlukan adanya penambahan RTH yang baru dalam waktu 20 tahun ke depan. Upaya peningkatan intensitas dan kualitas RTH sebagai cara meningkatkan kualitas lingkungan perkotaan sekaligus penyeimbang fungsi ekologis perkotaan. Kebutuhan ruang terbuka hijau di wilayah Kecamatan Batu Sopang adalah sebesar 30\% dari total luas penggunaan lahan yang ada yakni terbagi atas $20 \%$ ruang terbuka hijau publik dan $10 \%$ untuk ruang terbuka hijau privat.
\end{abstract}

Kata Kunci : manajemen aset fasilitas, Batu Sopang, GSP, Peta Citra, RTH.

\section{PENDAHULUAN}

Meningkatnya permintaan lahan untuk pemukiman dan pembangunan infrastruktur akan berimplikasi pada peningkatan iklim mikro. Iklim mikro yang terus meningkat akan berdampak pada gangguan kesehatan dan berpotensi menimbulkan bencana alam.

Ruang Terbuka Hujau (RTH) merupakan Fasilitas Perkotaan yang wajib diadakan dan dikelola dengan baik. Perencanaan RTH merupakan salah satu aspek Manajemen Aset Fasilitas yang sangat penting (Soemitro \& Suprayitno 2018).

Perubahan RTH berkorelasi positif dengan jumlah fasilitas ekonomi, jarak ke fasilitas pendidikan, jarak ke pusat kota, serta luas lahan kosong, sedangkan yang berkorelasi negatif adalah jumlah fasilitas pendidikan, jumlah fasilitas sosial (Setyani et al, 2017). 
Tujuan pembentukan RTH di wilayah perkotaan bisa dirumuskan dalam dua pokok rumusan sebagai berikut.

a. Meningkatkan mutu lingkungan hidup perkotaan yang nyaman, segar, indah, bersih dan sebagai sarana pengaman lingkungan perkotaan

b. Menciptakan keserasian lingkungan alam dalam lingkungan binaan yang berguna untuk kepentingan masyarakat Samsudi (2010).

Terdapat hubungan antara kepadatan penduduk dan peningkatan iklim mikro (dikenal dengan istilah Urban Heat Island (UHI). Menurut Maru dan Ahmad (2015) penurunan RTH telah menyebabkan peningkatan suhu mikro di Jakarta, Balikapan dan Makassar sebesar $0,124^{0} \mathrm{C}$.

Menurut Maru (2017), perkembangan fenomena UHI di Kota Makassar dari tahun 2010 hingga tahun 2015 sangat signifikan.Suhu yang tinggi pada umumnya terjadi pada kawasan terbangun baik itu perumahan ataupun perkantoran.

Berdasarkan RTRW Kabupaten Paser Tahun 2015 - 2035 wilayah Perkotaan Batu Sopang (Ibu Kota Kecamatan Batu Sopang) merupakan Pusat Kegiatan Lokal (PKL) dengan fungsi sebagai pusat pemerintahan, pelayanan sosial dan ekonomi, perdagangan dan jasa, kota persinggahan, produksi dan pemasaran hasil sumber daya alam, permukiman dan pelayanan lainnya dengan skala kabupaten sekaligus pusat-pusat pengembangan yang setiap kegiatan intensitasnya semakin meningkat dari waktu ke waktu sehingga dibutuhkan pengaturan ruang yang baik demi kelangsungan pelaksanaan kegiatan-kegiatan ekonomi, sosial, budaya serta pemerintahan secara aman, nyaman, serasi dan berkelanjutan. Penduduk yang masih terkonsentrasi di sekitar sempadan sungai menimbulkan pemandangan tidak sedap dan kurang sehat.

UN-Habitat (2002) menyebutkan ada 5 indikator untuk menentukan perbaikan lingkungan kumuh, yatu:

a) Porporsi penduduk perkotaan dengan akses berkelanjutan terhadap sumber air bersih.

b) Proporsi penduduk perkotaan dengan akses berkelanjutan terhadap sanitasi yang baik.

c) Proporsi penduduk perkotaan dengan akses berkelanjutan terhadap lahan.

d) Proporsi penduduk perkotaan dengan akses berkelanjutan terhadap ketersediaan unit perumahan yang layak.

e) Proporsi penduduk perkotaan dengan akses berkelanjutan terhadap ruang tamu yang memadai.

Lebih lanjut UN-Habitat (2003) menggambarkan suatu keadaan pemukiman kumuh yang tidak aman kepemilikan, kurangnya layanan dasar (terutama air dan sanitasi), stuktur bangunann yang tidak memadai (terkadang tidak aman), kepadatan penduduk, dan berada di lokasi tanah yang rawan.

Salah satu cara yang dapat dilakukan dalam menjaga keseimbangan ekosistem di perkotaan yang baru berkembang adalah dengan mengalokasikan Ruang Terbuka Hijau. Beberapa studi menunjukkan bahwa RTH banyak memiliki manfaat bagi kehidupandi perkotaan. Schipperijn (2010) menginvetarisir manfaat langsung maupun tidak langsung dari RTH, antara lain : bermanfaat terhadap kesehatan fisik (udara segar/sejuk akan memberi efek kesembuihan terhadap jenis penyakit tertentu pada manusia), kesehatan psikis (tempat refreshing dan menurunkan stress), sosial (tempat berkangsungnya interaksi manusia satu dengan lainnya), ekonomi (membuka peluang usaha) dan lingkungan (keseimbangan ekosistem). Namun, kehadiran RTH juga dapat menimbukan dampak negatif, antara lain: beberapa jenis tanaman yang ditanam di RTH dapat meninbulkan alergi (bagi masnusia yang rentan), berpotensi menimbulkan konflik sosial (bagi pihak-pihak yang memiliki kepentingan tertentu di atasnya), dan masalah yang timbul akibat dari pohon-pohon mati/tumbang. Artinya di sini penentuan lokasi RTH harus berhati-hati agar tidak timbul konflik kepentingan di 
kemudian hari dan juga vegetasi yang tumbuh di atasnya tidak membahayakan bagi penduduk yang tinggal di sekitarnya.

Hasil penelitian di atas dikuatkan oleh artikel yang ditulis Anonim (2018), bahwa keberadaan RTH secara ekonomi memberi manfaat :

a. Meningkatkan daya tarik suatu daerah

b. Meingkatkan nilai jual properti

c. Mendorong investasi lokal

d. Menghasilkan pendapatan bagi bisnis lokal

e. Menciptakan peluang kerja

f. Melindungi tempat tinggal dan aktifitas bisnis dari risiko banjir.

Pembangunan RTH dengan konsep Green Spatial Planning (GSP) juga mempertimbangkan kapasitas drainase agar tersedia air yang cukup bagi tumbuh tanaman dan air limpasan dapat mengalir secara normal. Dalam rangka normalisasi drainase, maka untuk mengurangi genangan yang disebabkan limpasan permukaan, diperlukan rehabilitasi sedangkan untuk mengurangi beban drainase diperlukan pemindahan (Cahya et al, 2018).

Berdasar pada uraian di atas, penulis tertarik untuk mengetahui potensi Ruang Terbuka Hijau yang masih memungkinkan untuk dimantapkan, mengingat kondisi Batu Sopang yang telah dipenuhi aktifitas sosial dan ekonomi masyarakat.

\section{RUANG LINGKUP}

Lingkup wilayah penelitian adalah Kecamatan Batu Sopang dengan luas 1.174,51 Ha. Dari luas wilayah yang ada akan ditentukan lokasi-lokasi Ruang Terbuka Hijau dengan menerapkan konsep Green Spatial Planning.

Selanjutnya, hasil yang diharapkan adalah diperolehnya lokasi RTH yang proporsional di dalam wilayah Kecamatan Batu Sopang Kabupaten Paser.

\section{BAHAN DAN METODE}

Bahan-bahan yang digunakan dalam penelitian ini berupa: peta topografi dalam skala 1 : 5.000 atau skala lebih besar berdasarkan hasil pengukuran di lapangan, peta tutupan lahan, peta administrasi wilayah, peta pemilikan lahan, peta geologi, hidrologi, dan klimatologi.

Teknik analisis data yang digunakan sebagai berikut :

\section{Analisis Identifikasi Rencana Ruang Terbuka Hijau}

Analisis sebaran RTH di Kecamatan Batu Sopang merupakan hasil klasifikasi RTH yang diperoleh dari citra ALOS AVNIR-2 dan peta administratif. Perhitungan luasan RTH dilakukan dengan menggunakan data spasial dasar dan tematik menggunakan ArcGIS 10.1. 
Tabel 1. Fungsi dan Penerapan RTH pada Beberapa Tipologi Kawasan Perkotaan

\begin{tabular}{lll}
\hline Tipologi Kawasan & Karakteristik RTH & \\
\hline Perkotaan & Fungsi Utama & Penerapan Kebutuhan RTH. \\
Pantai & $\begin{array}{l}\text { Pengamanan pantai, } \\
\text { Sosial, mitigasi } \\
\text { Bencana. }\end{array}$ & $\begin{array}{l}\text { Berdasarkan luas wilayah dan fungsi } \\
\text { tertentu. }\end{array}$ \\
\hline $\begin{array}{l}\text { Konservasi tanah, } \\
\text { konservasi air, } \\
\text { keanekaragaman } \\
\text { hayati. }\end{array}$ & $\begin{array}{l}\text { Berdasarkan luas wilayah } \\
\text { dan fungsi tertentu. }\end{array}$ \\
Pegunungan & $\begin{array}{l}\text { Mitigasi/evakuasi } \\
\text { Bencana. }\end{array}$ & Berdasarkan fungsi tertentu. \\
\hline Rawan Bencana & $\begin{array}{l}\text { Dasar perencanaan } \\
\text { kawasan sosial. }\end{array}$ & $\begin{array}{l}\text { Berdasarkan fungsi tertentu } \\
\text { dan jumlah penduduk. }\end{array}$ \\
\hline $\begin{array}{l}\text { Berpenduduk } \\
\text { jarang - sedang }\end{array}$ & $\begin{array}{l}\text { Ekologis, sosial, } \\
\text { Hidrologis. }\end{array}$ & $\begin{array}{l}\text { Berdasarkan fungsi tertentu } \\
\text { dan jumlah penduduk. }\end{array}$ \\
\hline $\begin{array}{l}\text { Berpenduduk } \\
\text { Padat }\end{array}$ & Sumber: Peraturan Menteri PU No 5 Tahun 2008 &
\end{tabular}

\section{Analisis Kawasan}

Analisis kawasan ini dilakukan untuk mengenali karakteristik sumber daya alam tersebut, dengan menelaah kemampuan dan kesesuaian lahan, agar penggunaan lahan dalam pengembangan wilayah dan/atau kawasan dapat dilakukan secara optimal dengan tetap memperhatikan keseimbangan ekosistem.

\section{PEMBAHASAN}

Konsep Green Spatial Planning memadukan tata ruang dengan pengelolaan unsur-unsur biofisik dan interaksi sosial dalam suatu kawasan. Pengelolaan tata ruang tidak hanya membagi-bagi kawasan namun juga menciptakan kondisi lingkungan yang nyaman, aman dan harmoni. Penentuan kawasan dengan mempertimbangan laju pertumbuhan penduduk, aktifitas yang berlangsung dan upaya meminimalisir terjadinya dampak negatif akibat pembangunan. Dalam pemantapan Ruang Terbuka Hijau yang berbasis Green Spatial Planning, maka halhal yang ditonjolkan di sini adalah pembagian kawasan yang mendukung pada keseimbangan ekosistem dan pengisian ruang-ruang terbuka dengan jenis-jenis flora yang memiliki kemampuan dalam menyerap gas $\mathrm{CO} 2$, penghasil gas $\mathrm{O} 2$, mengurangi penetrasi intensitas sinar matahari langsung ke permukaan bumi, menahan tekanan angin, serta memberi kesan estetika sekaligus pelestarian.

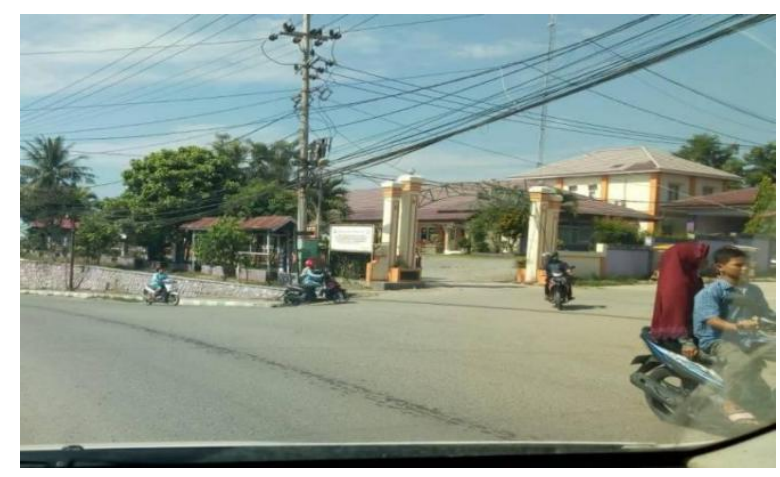

Gambar 1. Kondisi Eksisting Kawasan Perkotaan Batu Sopang

Ruang kota, baik berupa lapangan maupun koridor/jaringan, merupakan salah satu elemen rancang kota yang sangat penting dalam pengendalian kualitas lingkungan ekologis dan sosial (Shirvani 1985). 
Penghijuan kota dalam bentuk hutan kota di pusat kota/ sub pusat kota sangat dianjurkan dibandingkan sekedar ruang terbuka hijau, dalam fungsinya turut meredam laju peningkatan suhu udara global (Sangkertadi dan Syafriny 2008).

Secara garis besar, RTH dapat dibangun di lokasi-lokasi publik maupun privat. Berdasarkan Undang-Undang No. 26 Tahun 2007 tentang Penataan Ruang, proporsi luas RTH minimal $30 \%$ dari luas kota, yang terbagi atas $20 \%$ berupa RTH publik (dikelola pemerintah daerah) dan 10\% RTH privat (dimiliki masyarakat dan swasta). Terkait dengan penelitian ini, dengan mempertimbangankan bahwa Ruang Terbuka Hijau (RTH) adalah area memanjang/jalur dan atau mengelompok, yang penggunaannya lebih bersifat terbuka, tempat tumbuh tanaman, baik yang tumbuh tanaman secara alamiah maupun yang sengaja ditanam, maka potensi RTH di dalam kawasan perkotaan Batu Sopang berada di dalam zona lindung.

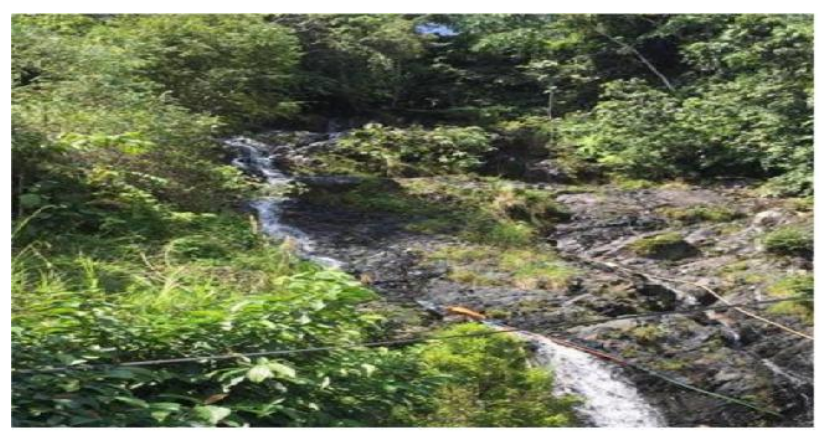

Gambar 2. Kondisi Tepi Sungai Rawan Longsor

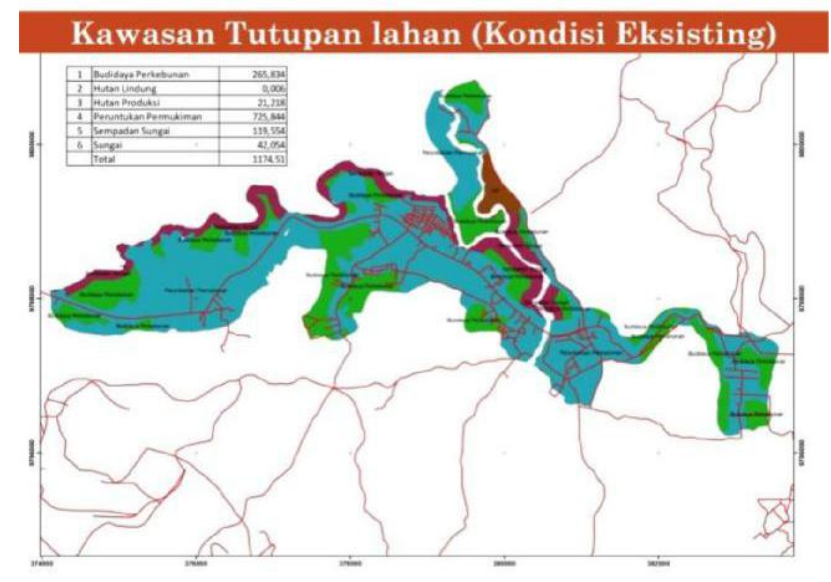

Gambar 3. Kondisi Eksisting Wilayah Batu Sopang

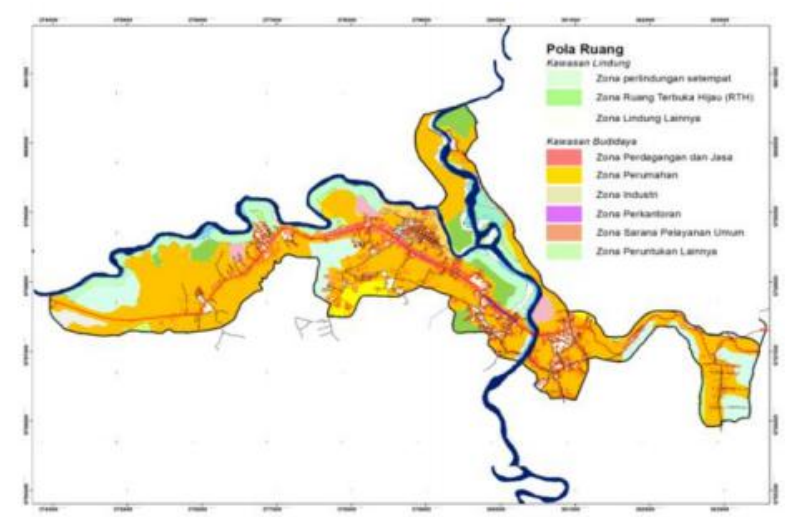

Gambar 4. Peta Pola Ruang Batu Sopang 
Penataan sempadan sungai di wilayah perkotaan mengacu pada PP No. 38 Tahun 2011, yaitu secara bertahap mengatur sempadan sungai sesuai peraturan lebar sempadan, serta dipertahankan sebagai jalur hijau yang harus bersih dari bangunan dengan cara tidak mengizinkan berdirinya bangunan baru ataupun mengembangkan bangunan yang ada.

Tepi sungai ditetapkan berdasarkan proses perubahan fisik morphologi, hidraulik, ekologi dan sosial/keamanan masyarakat oleh sebab itu sempadan sungai merupakan garis perlindungan sungai guna mencegah terjadinya kerusakan sungai akibat perilaku manusia Manfaat sempadan sungai terhadap konservasi sungai (baik ekologi, hidraulik dan morphologinya) sangat signifikan. Lebar sempadan untuk konservasi perbaikan kualitas air, adalah $5 \mathrm{~m}$ sampai $80 \mathrm{~m}$, untuk konservasi habitat aquatik $3 \mathrm{~m}$ sampai $30 \mathrm{~m}$ dan untuk konservasi habitat terestrial adalah $30 \mathrm{~m}$ sampai $500 \mathrm{~m}$ sedangkan untuk memberikan ruang meandering dan perlindungan terhadap banjir diperlukan sempadan sungai $5 \mathrm{~m}$ sampai $90 \mathrm{~m}$ (Maryono 2005). Menurut Sunarhadi et al (2015), kriteria dalam menentukan sempadan sungai adalah kelas kemampuan lahan dan luas DAS tangkapan. Lebar sempadan sungai terdiri atas sempadan mutlak dan sempadan penyangga. Sempadan mutlak ditetapkan selebar 6 meter. Sempadan penyangga ditetapkan.

a. 60 meter untuk sungai besar di lahan dengan Kelas Kemampuan Lahan I sampai V

b. 35 meter untuk sungai besar di lahan dengan Kelas Kemampuan Lahan I sampai V

c. 35 meter untuk sungai di lahan dengan Kelas

Kemampuan Lahan VI sampai VIII

a. Pada kondisi sempadan sungai digunakan masyarakat pinggiran kota untuk membangun rumah perlu dilakukan penertiban dan desain selaras dengan lin. Sungai bertanggul di dalam kawasan perkotaan. Sempadan sungai bertanggul di dalam kawasan perkotaan ditentukan paling sedikit berjarak 3 (tiga) meter dari tepi luar kaki tanggul sepanjang alur sungai.

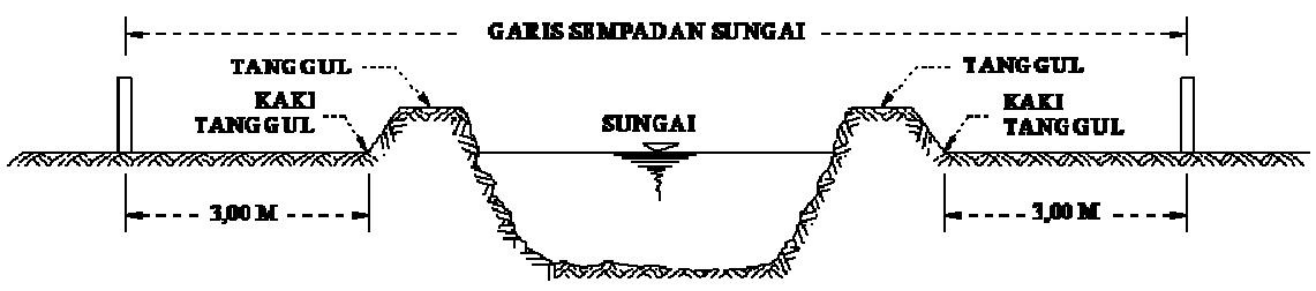

Gambar 5. Dimensi Sempadan Sungai Bertanggul Dalam Kawasan Perkotaan

b. Sungai tak bertanggul di luar kawasan perkotaan. Sempadan sungai tidak bertanggul di dalam kawasan perkotaan dapat ditentukan pada jarak

1) Paling sedikit berjarak 10 (sepuluh) meter dari tepi kiri dan kanan palung sungai sepanjang alur sungai, dalam hal kedalaman sungai kurang dari atau sama dengan 3 (tiga) meter.

2) Paling sedikit berjarak 15 (lima belas) meter dari tepi kiri dan kanan palung sungai sepanjang alur sungai, dalam hal kedalaman sungai kurang dari atau sama dengan 3 (tiga) meter sampai dengan 20 meter. Paling sedikit berjarak 30 (tiga puluh) meter dari tepi kiri dan kanan palung sungai sepanjang alur sungai, dalam hal kedalaman sungai lebih dari 20 (dua puluh) meter. 


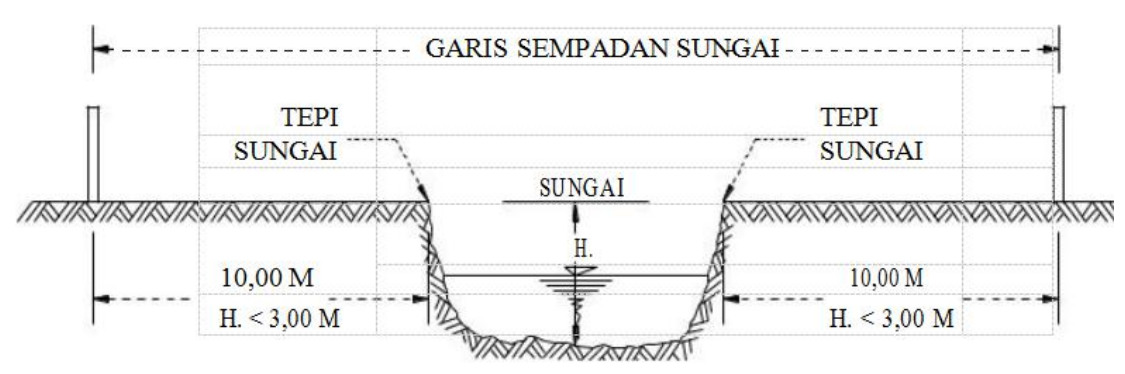

Gambar 6. Dimensi Sempadan Sungai Tak Bertanggul di Luar Kawasan Perkotaan

\section{Perkotaan}

Untuk mempertahankan kelestarian fungsi sungai, di sekitar sempadan tidak berkembang bangunan-bangunan liar ataupun permanen. Namun upaya pelestarian kawasan sempadan kurang optimal, sungai-sungai yang ada kurang dijaga di kelestariannya sehingga terjadibanjir

Selanjutnya untuk menentukan jenis vegetasi yang cocok ditanam di RTH, seyoganya memenuhi kriteria sebagai berikut:

1) Tidak beracun, tidak berduri, dahan tidak mudah patah, perakaran tidak mengganggu pondasi

2) Tajuk cukup rindang dan kompak, tetapi tidak terlalu gelap.

3) Ketinggian tanaman bervariasi, warna hijau dengan variasi warna lain seimbang.

4) Perawakan dan bentuk tajuk cukup indah dengan kecepatan tumbuh sedang.

5) Berupa habitat tanaman lokal dan tanaman budidaya.

6) Jenis tanaman tahunan atau musiman.

7) Jarak tanam setengah rapat sehingga menghasilkan keteduhan yang optimal.

8) Tahan terhadap hama penyakit tanaman.

9) Mampu menjerap dan menyerap cemaran udara dan lingkungan hidup.

10) Jenis vegetasi yang dipilih berupa pohon tahunan, perdu, dan semak ditanam secara Berkelompok atau menyebar berfungsi sebagai pohon pencipta iklim mikro atau sebagai pembatas antar kegiatan.

Pemilhan jenis vegetasi intuk dimasukkan melengkapi RTH Batu Sopang berdasarkan analisis kesesuaian lahan, antara lain : damar (Agathis alba), daun kupu-kupu (Bauhinia purpurea), lamtoro gung (Leucaena leucocephala), akasia (Acaciaauriculi formis), dan beringin (Ficus benyamina) (Aipassa et al., 2017).

Apabila potensi RTH yang ada dikurangi, maka akan berdampak buruk terhadap iklim mikro. Penelitian mengenai dampak dari pengurangan RTH. Menurut Badan Pengkajian Kebijakan Iklim dan Mutu Industri pada tahun 2012 (Rawung, 2015), karbon dioksida (CO2) memberikan kontribusi terbesar terhadap pemanasan global diikuti oleh gas methan $(\mathrm{CH} 4)$. Lebih dari 75\% komposisi GRK di atmosfir adalah CO2.

Kondisi RTH digambarkan dengan kerapatan vegetasi, semakin rapat vegetasi maka semakin baik kondisi RTHnya. Semakin baik kondisi RTH maka semakin rendah suhu udara dan sebaliknya semakin jelek kondisi RTH maka suhu udaranya semakin tinggi (Sangkertadi \& Syafriny 2008). Setiap pengurangan 50\% RTH menyebabkan peningkatan suhu udara sebesar 0.4 hingga $1.8^{\circ} \mathrm{C}$, sedangkan penambahan RTH $50 \%$ hanya menurunkan suhu udara sebesar 0.2 hingga $0.5^{\circ} \mathrm{C}$ (Effendy, 2009).

Selanjutnya agar proses pembangunan yang ada di dalam wilayah Batu Sopang dapat terjadi secara berkelanjutan, maka perlu menerapkan empat asas Evrianto (2012) sebagai berikut. 
(e)ISSN 2615-1847 (p)ISSN 2615-1839

Jurnal Manajemen Aset Infrastruktur \& Fasilitas - Vol.3, Edisi Khusus 2, Juni 2019

Tabel 2. Kebutuhan Pengembangan RTH Desa

\begin{tabular}{|c|c|c|c|c|c|c|}
\hline \multirow{2}{*}{ No. } & \multirow{2}{*}{ Desa } & \multirow{2}{*}{$\begin{array}{l}\text { Jenis } \\
\text { Fasilit as }\end{array}$} & \multirow{2}{*}{$\begin{array}{l}\text { Standar } \\
\text { Penduduk }\end{array}$} & \multirow{2}{*}{$\begin{array}{l}\text { Luas } \\
\left(m^{2}\right)\end{array}$} & \multicolumn{2}{|c|}{ Kebutuhan Tahun 2038} \\
\hline & & & & & Jml. Pddik & $\begin{array}{l}\text { Luas } \\
\left(\mathrm{m}^{2}\right)\end{array}$ \\
\hline 1 & 2 & 3 & 4 & 5 & 6 & 7 \\
\hline 1 & $\begin{array}{l}\text { Sungai } \\
\text { Terk }\end{array}$ & $\begin{array}{l}\text { Lapangan } \\
\text { Volley/Badminton/Open } \\
\text { Space }\end{array}$ & 2.500 & 1.250 & 36.514 & 10.990 \\
\hline \multirow{9}{*}{2} & \multirow{9}{*}{$\begin{array}{l}\text { Bat } \\
\text { Kajegng }\end{array}$} & Lapangan Sepakbola & 30.000 & 9.000 & 36.514 & 9.000 \\
\hline & & $\begin{array}{l}\text { Lapangan } \\
\text { tenn B/Basket/Open Space }\end{array}$ & 120000 & 24.000 & 36.514 & 0.00 \\
\hline & & Taman & 30.000 & 1.300 & 36.514 & 1.300 \\
\hline & & GOR & 480000 & 144.000 & 36.514 & 0 \\
\hline & & $\begin{array}{l}\text { Lapangan } \\
\text { Volley/Badminton/Open } \\
\text { Space }\end{array}$ & 2.500 & 1.250 & 25.867 & 2.500 \\
\hline & & Lapangan Sepakbola & 30.000 & 9.000 & 25.867 & 0 \\
\hline & & $\begin{array}{l}\text { Lapangan } \\
\text { tennis/Basket/Open Space }\end{array}$ & 120000 & 24.000 & 25.867 & 0 \\
\hline & & Taman & 30.000 & 1.300 & 25.867 & 1.300 \\
\hline & & GOR & 480000 & 144.000 & 25.867 & 0 \\
\hline \multirow[t]{5}{*}{3} & \multirow[t]{5}{*}{$\begin{array}{l}\text { Batu } \\
\text { kajang }\end{array}$} & $\begin{array}{l}\text { Lapangan } \\
\text { Volley/Badminton/Open } \\
\text { Space }\end{array}$ & 2.500 & 1.250 & 23.431 & 3.750 \\
\hline & & Lapangan Sepakbola & 30.000 & 9.000 & 23.431 & 0 \\
\hline & & $\begin{array}{l}\text { Lapangan } \\
\text { tennis/Basket/Open Space }\end{array}$ & 120000 & 24.000 & 23.431 & 0 \\
\hline & & Taman & 30.000 & 1.300 & 23.431 & 1.300 \\
\hline & & GOR & 480000 & 144.000 & 23.431 & 0 \\
\hline \multirow[t]{5}{*}{4} & \multirow[t]{5}{*}{ Kasungai } & $\begin{array}{l}\text { Lapangan } \\
\text { Volley/Badminton/Open } \\
\text { Space }\end{array}$ & 2.500 & 1.250 & 48.086 & 2.500 \\
\hline & & Lapangan Sepakbola & 30.000 & 9.000 & 48.086 & 0 \\
\hline & & $\begin{array}{l}\text { Lapangan } \\
\text { tennis/Basket/Open Space }\end{array}$ & 120000 & 24.000 & 48.086 & 0 \\
\hline & & Taman & 30.000 & 1.300 & 48.086 & 0 \\
\hline & & GOR & 480000 & 144.000 & 48.086 & 0 \\
\hline \multirow[t]{5}{*}{5} & \multirow[t]{5}{*}{$\begin{array}{l}\text { Batu } \\
\text { Kajeng }\end{array}$} & $\begin{array}{l}\text { Lapangan } \\
\text { Volley/Badminton/Open } \\
\text { Space }\end{array}$ & 2.500 & 1.250 & 24.480 & 3.750 \\
\hline & & Lapangan Sepakbola & 30.000 & 9.000 & 24.480 & 0 \\
\hline & & $\begin{array}{l}\text { Lapangan } \\
\text { tennis/Basket/Open Space }\end{array}$ & 120000 & 24.000 & 24.480 & 0 \\
\hline & & Taman & 30.000 & 1.300 & 24.480 & 1.300 \\
\hline & & GOR & 480000 & 144.000 & 24.480 & 0 \\
\hline \multirow[t]{4}{*}{6} & \multirow[t]{4}{*}{$\begin{array}{l}\text { Sopang } \\
\text { Sopats }\end{array}$} & $\begin{array}{l}\text { Lapangan } \\
\text { Volley/Badminton/Open } \\
\text { Space }\end{array}$ & 2.500 & 1.250 & 21.632 & 5.000 \\
\hline & & Lapangan Sepakbola & 30.000 & 9.000 & 21.632 & 0 \\
\hline & & $\begin{array}{l}\text { Lapangan } \\
\text { tennis/Basket/Open Space }\end{array}$ & 120000 & 24.000 & 21.632 & 0 \\
\hline & & $\begin{array}{l}\text { Taman } \\
\text { GOR } \\
\end{array}$ & $\begin{array}{l}30.000 \\
480.000 \\
\end{array}$ & $\begin{array}{l}1.300 \\
144000 \\
\end{array}$ & $\begin{array}{l}21.632 \\
21.632 \\
\end{array}$ & $\begin{array}{l}1.300 \\
0\end{array}$ \\
\hline \multirow[t]{5}{*}{7} & \multirow[t]{5}{*}{$\begin{array}{l}\text { Batu } \\
\text { Kajang }\end{array}$} & $\begin{array}{l}\text { Lapangan } \\
\text { Volley/Badminton/Open } \\
\text { Space }\end{array}$ & 2500 & 1.250 & 42.902 & \\
\hline & & Lapangan Sepakbola & 30.000 & 9.000 & 42.902 & \\
\hline & & $\begin{array}{l}\text { Lapangan } \\
\text { tennis/Basket/Open Space }\end{array}$ & 120.000 & 24.000 & 42.902 & \\
\hline & & Taman & 30.000 & 1.300 & 42.902 & 1.300 \\
\hline & & GOR & 480.000 & 144000 & 42.902 & \\
\hline
\end{tabular}


Tabel 2. Lanjutan...

\begin{tabular}{|c|c|c|c|c|c|c|}
\hline 1 & 2 & 3 & 4 & 5 & 6 & 7 \\
\hline \multirow[t]{5}{*}{8} & \multirow[t]{5}{*}{ Songka } & $\begin{array}{l}\text { Lapangan } \\
\text { Volley/Badminton/Open } \\
\text { Space }\end{array}$ & 2500 & 1.250 & 41.023 & \\
\hline & & Lapangan Sepakbola & 30.000 & 9.000 & 41.023 & \\
\hline & & $\begin{array}{l}\text { Lapangan } \\
\text { tennis/Basket/Open Space }\end{array}$ & 120.000 & 24.000 & 41.023 & \\
\hline & & Taman & 30.000 & 1.300 & 41.023 & 1.300 \\
\hline & & GOR & 480.000 & 144000 & 41.023 & \\
\hline \multirow[t]{5}{*}{9} & \multirow[t]{5}{*}{ Kasungai } & $\begin{array}{l}\text { Lapargan } \\
\text { Vollev/Badminton/Open } \\
\text { Space }\end{array}$ & 2500 & 1.250 & 29.008 & \\
\hline & & Lapangan Sepaksbola & 30.000 & 9.000 & 29.708 & \\
\hline & & $\begin{array}{l}\text { Lapangan } \\
\text { tenns//Basket/Open Space }\end{array}$ & 120000 & 24.000 & 29.708 & \\
\hline & & Tamran & 30.000 & 1300 & 29.708 & 1.300 \\
\hline & & GOR & 480000 & 144000 & 29.708 & \\
\hline \multirow[t]{5}{*}{10} & \multirow[t]{5}{*}{$\begin{array}{l}\text { Sunggi } \\
\text { Terik }\end{array}$} & $\begin{array}{l}\text { Lapangan } \\
\text { Volley/laadminton/Open } \\
\text { Space }\end{array}$ & 2.500 & 1.250 & 36.180 & \\
\hline & & Lapangan Sepakbola & 30.000 & 9.000 & 36.180 & \\
\hline & & $\begin{array}{l}\text { Lapangan } \\
\text { tennis/Basket/open Space }\end{array}$ & 120000 & 24.000 & 36.180 & \\
\hline & & Taman & 30.000 & 1.300 & 36.180 & 1.300 \\
\hline & & GOR & 480000 & 144000 & 36.180 & \\
\hline \multirow[t]{5}{*}{$\overline{11}$} & \multirow[t]{5}{*}{$\begin{array}{l}\text { Bastu } \\
\text { Kajang }\end{array}$} & $\begin{array}{l}\text { Lapargan } \\
\text { Volley/Badminton/Open } \\
\text { Space }\end{array}$ & 2.500 & 1.250 & 43.148 & \\
\hline & & Lapangan Sepakbola & 30.000 & 9.000 & 43.148 & \\
\hline & & $\begin{array}{l}\text { Lapangan } \\
\text { tennis/Basket/Open Space }\end{array}$ & 120000 & 24.000 & 43.148 & \\
\hline & & Taman & 30.000 & 1.300 & 43.148 & 1.300 \\
\hline & & GOR & 480000 & 144000 & 43.148 & \\
\hline \multirow[t]{5}{*}{12} & \multirow[t]{5}{*}{$\begin{array}{l}\text { Eatu } \\
\text { Kajang }\end{array}$} & $\begin{array}{l}\text { Lapangan } \\
\text { Volley/Badminton/Open } \\
\text { Space }\end{array}$ & 2.500 & 1.250 & 26.276 & \\
\hline & & Lapangan Sepakbola & 30.000 & 9.000 & 26.276 & \\
\hline & & $\begin{array}{l}\text { Lapangan } \\
\text { tenni/Basket/Open Space }\end{array}$ & 120000 & 24.000 & 26.276 & \\
\hline & & Taman & 30.000 & 1.300 & 26.276 & 1.300 \\
\hline & & GOR & 480000 & 144000 & 26.276 & \\
\hline \multirow[t]{5}{*}{13} & \multirow[t]{5}{*}{ Kassungai } & $\begin{array}{l}\text { Lapangan } \\
\text { Volley/Badminton/Open } \\
\text { Space }\end{array}$ & 2.500 & 1.250 & 43.609 & \\
\hline & & Lapangan Sepaktola & 30.000 & 9.000 & 43.609 & \\
\hline & & $\begin{array}{l}\text { Lapargan } \\
\text { tennis/lasket/Open Space }\end{array}$ & 120000 & 24.000 & 43.609 & \\
\hline & & Taman & 30.000 & 1.300 & 43.609 & 1.300 \\
\hline & & GOR & 480000 & 144000 & 43.609 & \\
\hline \multirow[t]{5}{*}{14} & \multirow[t]{5}{*}{ Songkai } & $\begin{array}{l}\text { Lapangan } \\
\text { Volley/Badminton/Open } \\
\text { Space }\end{array}$ & 2.500 & 1.250 & 3.907 & \\
\hline & & Lapargan Sepakbola & 30.000 & 9.000 & 3.907 & \\
\hline & & $\begin{array}{l}\text { Lapangan } \\
\text { tenni/Basket/Open Space }\end{array}$ & 120000 & 24.000 & 3.907 & \\
\hline & & Taman & 30.000 & 1.300 & 3.907 & 1.300 \\
\hline & & GOR & 480000 & 144000 & 3.907 & \\
\hline
\end{tabular}

\section{KESIMPULAN}

Kesimpulan yang dapat ditarik, bahwa dengan menggunakan konsep Green Spatial Planning (GSP) diperoleh luas potensi RTH di Batu Sopang sebesar 265,83 ha walaupun hasil perhitungan untuk mencapai $20 \%$ dari luas lahan memerlukan luas RTH Privat sebesar 234,90 ha. Namun demikian masih terdapat sempadan sungai yang dapat dikelola menjadi RTH, dengan luas 97,28 Hektar.

\section{SARAN}

Pada masa mendatang, perlu peningkatan kuantitas dan kualitas ruang terbuka hijau untuk meningkatkan kualitas lingkungan perkotaan sekaligus penyeimbang fungsi ekologis perkotaan mengingat Ruang Terbuka Hijau yang ada masih dapat ditingkatkan dengan 
menerapkan konsep "green roof" yaitu memanfaatkan atap di kawasan pemukiman padat penduduk dan rumah berlantai dua atau lebih.

\section{DAFTAR PUSTAKA}

Aipassa, Marlon I., Ruslim, Y. \& Sukartiningsih, Ibrahim (2017). Ruang Terbuka Hijau Pada Beberapa Kota di Kaliamntan Timur. Mulawarman University Press. Samarinda.

Anonim (2018). The economic value of our greenspaces. The Land Trust (2018). The Economic Value of Our Green Spaces. The landtrust.org.uk/wpcontent/uploads/2018/02/ diunduh tanggal 12-1-2019.

Cahya, Evi, N., Andawayantim, U. \& Resmani, E. (2018). "Analysis of Drainage Capacity and Rehabilitation Subjected to Rainfall and Reverse Flow of Marengan River as a Main Drain in Sumenep City, Indonesia". Civil and Environmental Science Journal (Civense), Vol. 1 (2): 080-087.

Effendy, Dobri (2009). "Dampak Pengurangan Ruang Terbuka Hijau (RTH) Perkotaan Terhadap Peningkatan Suhu Udara dengan Metode Penginderaan Jauh". J. Agromet 23 (2): $169-181$.

Evrianto, Wulfram, I.(2012). Selamatkan Bumi Melalui Konstruksi Hijau : Perencanaan, Pengadaan, Konstruksi \& Operasi. Andi. Yogyakarta.

Maru, R. \& Ahmad, S. (2015). "The Relationship between Temperature Patterns and Urban Morfometri in the Jakarta City, Indonesia". Asian Journal of Atmospheric Environment. Vol. 9 (2), pp. 128-136, June (2015). ISSN (Online) 2287-1160.ISSN (Print) 1976-6912. DOI: http://dx.doi.org/10.5572/ajae.2015.9.2.128.(diaksestanggal 14 Desember 2018).

Maru, R. (2017). "Perkembangan Fenomena Urban Heat Island”. Simposium Nasional MIPA. Universitas Negeri Makassar (diakses tanggal 14 Desember 2018).

Maryono, A. (2005). Menangani Banjir, Kekeringan dan Lingkungan. Gajah Mada Press. Yogyakarta.

Maryono, Agus (2014). Pengelolaan Kawasan Sempadan Sungai Dengan Pendekatan Integral: Peraturan, Kelembagaan, Tata Ruang, Sosial, Morfologi, Ekologi, Hidrologi dan Keteknikan. Gadjah Mada University Press.Yogyakarta.

Rawung, F. Chiarly (2015)."Efektivitas Ruang Terbuka Hijau (RTH) Dalam Mereduksi Emisi Gas Rumah Kaca (GRK) Di Kawasan Perkotaan Boroko". Media Matrasain 12 (2) : 17 -32 .

Samsudi (2010). "Ruang Terbuka Hijau Kebutuhan Tata Ruang Perkotaan Kota Surakarta". Journal of Rural and Development, Vol. 1 (1):11 - 19.

Sangkertadi \& R. Syafriny (2008). "Upaya Peredaman Laju Peningkatan Suhu Udara Perkotaan Melalui Optimasi Penghijauan”. Ekoton 8(2):41-48.

Schipperijn, J. (2010). "Use of Urban Green Space". Forest \& Landscape Research No. 45, 2010. Frederiksberg: Forest \& Landscape Denmark.

Setyani, W., Sitorus, S.R.P \& Panuju D.R. (2017). Analisis Ruang Terbuka Hijau dan Kecukupannya Di Kota Depok. Buletin Tanah dan Lahan, 1 (1):121-127.

Shirvani, Hamid (1985). Urban Design Process. Van Nostrand Heinhold Company. New York.

Sunarhadi, R.M.A., Suharjo, A.N., Anna, B.S. \& Anwar (2015). "Penentuan Lebar Sempadan Sebagai Kawasan Lindung Sungai di Kabupaten Sukoharjo". Makalah Seminar Nasional Konservasi dan Pemanfaatan Sumber Daya Alam. PKLH - FKIPUNS.

Soemitro, R.A.A. \& Suprayitno, H. (2018). "Pemikiran Awal tentang Konsep Dasar Manajemen Aset Fasilitas". Jurnal Manajemen Aset Infrastruktur \& Fasilitas, Vol.2, Sup.1, Juni 2018, Hal : 1- 13. 
UN-Habitat (2002). Expert Group on Urban Indicators : Secure Tenure, Slums and Global Sample of Cities. Urban Secretariat and Shelter Branch in Close Collaboration with United Nations Statistic Division and the Cities Alliances. Nairobi.

UN-Habitat (2003).The Challenge of Slums Global Report on Human Settlements. United Nations Human Settlements Programme. Nairobi. 
(e)ISSN 2615-1847 (p)ISSN 2615-1839

Jurnal Manajemen Aset Infrastruktur \& Fasilitas - Vol.3, Edisi Khusus 2, Juni 2019 